\title{
Retrograde Amnesia for Facts and Events: Findings from Four New Cases
}

\author{
Jonathan M. Reed ${ }^{1}$ and Larry R. Squire ${ }^{1,2,3}$ \\ Departments of ${ }^{1}$ Psychiatry and ${ }^{2}$ Neurosciences, University of California, San Diego, La Jolla, California 92093, and \\ 3Veterans Affairs Medical Center, San Diego, California 92161
}

Two patients with presumed hippocampal formation lesions and two patients with more extensive temporal lobe damage, all of whom became amnesic in a known year, were given tests of anterograde and retrograde memory function. The two patients with hippocampal formation lesions had moderately severe anterograde amnesia and limited retrograde amnesia for facts and events that affected, at most, the decade preceding the onset of amnesia. Content analysis could not distinguish the autobiographical recollections of the patients from the recollections of control subjects. The two patients with more ex- tensive temporal lobe damage had severe anterograde amnesia and extensive retrograde memory loss for both facts and events. The results suggest that whether retrograde amnesia is temporally limited or very extensive depends on whether the damage is restricted to the hippocampal formation or also involves additional temporal cortex.

Key words: retrograde amnesia; anterograde amnesia; hippocampal formation; medial temporal lobe; autobiographical memory; fact memory
Retrograde amnesia (RA) refers to loss of memory for information acquired before the onset of amnesia. The condition is commonly observed after medial temporal lobe or diencephalic pathology, and it has fascinated psychologists, biologists, and clinicians for over 100 years (Ribot, 1881). An understanding of RA should have considerable implications for understanding the organization of normal memory as well as the function of the damaged brain structures. Yet the facts themselves are not agreed on. For example, RA has been described as typically extensive and ungraded, affecting recent and very remote memories alike (Sanders and Warrington, 1971; Warrington, 1996). Alternatively, RA has been described as usually temporally graded, sparing remote memory (Marslen-Wilson and Teuber, 1975; Squire and Alvarez, 1995). With respect to what kind of memory impairment occurs, RA sometimes has been described as affecting both fact (semantic) memory and autobiographical (episodic) memory similarly (Verfaellie et al., 1995; Rempel-Clower et al., 1996). Alternatively, RA has been described as affecting autobiographical memory across a patient's entire lifetime and affecting fact memory to a much lesser degree (Nadel and Moscovitch, 1997).

There are several reasons why these issues have been slow to resolve. A major factor is that, even when quantitative neuropsychological testing is performed, adequate neuropathological information about the patients is not always available. Yet anatomical data could be fundamental to understanding similarities and differences in the behavioral findings. In some instances, useful anatomical information has been obtained from magnetic resonance imaging (MRI), although the amount of available detail

Received Dec. 18, 1997; revised Feb. 26, 1998; accepted March 4, 1998.

This research was supported by the Medical Research Service of the Department of Veterans Affairs, National Institute of Mental Health Grant MH24600, and National Institutes of Health Grant T32 AG00216. We thank Joyce Zouzounis, James Moore, Nicole Champagne, Lisa Stefanacci, and Stuart Zola for assistance.

Correspondence should be addressed to Dr. Larry R. Squire, Veterans Affairs Medical Center 116A, 3350 La Jolla Village Drive, San Diego, CA 92161.

Copyright (C) 1998 Society for Neuroscience $0270-6474 / 98 / 183943-12 \$ 05.00 / 0$ varies greatly across studies. Neurohistological data from postmortem examination, in conjunction with quantitative neuropsychological data about RA, are available for only four patients with lesions restricted bilaterally to the medial temporal lobe [R.B., Zola-Morgan et al. (1986); G.D., W.H., and L.M., RempelClower et al. (1996)]. In a few other cases of medial temporal lobe lesions, detailed neurohistological information is presented, but only clinical impressions are available about the RA (Victor et al., 1961; Penfield and Mathieson, 1974; Victor and Agamanolis, 1990).

Another major difficulty is that the study of past memory in amnesic patients relies necessarily on retrospective methods and imperfect tests. For tests of factual knowledge (e.g., public events tests), individuals vary widely in how much they know about the subject matter, independent of the influence of amnesia. For tests of autobiographical knowledge, it is often not possible to verify the accuracy of the recollections, and there are also difficult issues concerning how best to score the content of what is remembered.

The available data suggest that RA can vary considerably in its severity - from temporally limited RA covering up to a few years to more extensive, ungraded RA involving all of the decades covered by the tests (Squire, 1992; Hodges, 1994; Schmidtke and Vollmer, 1997). Many questions remain, however, about what kind of retrograde impairment is most typical in amnesia and what specific neuropathology is associated with the various presentations of RA. It also remains unclear whether autobiographical memory usually is affected to the same degree as fact memory or whether autobiographical memory usually is affected much more severely than fact memory.

We have assessed RA in four patients, three of whom had detailed MRI examinations to characterize the lesions. One has damage limited to the hippocampal formation, a second was not eligible for MRI but is presumed to have hippocampal formation damage based on etiology, and two others have hippocampal formation damage together with amygdala damage and additional temporal cortical damage. All of the patients were assessed with 
Table 1. Characteristics of amnesic patients

\begin{tabular}{|c|c|c|c|c|c|c|c|c|c|}
\hline \multirow[b]{2}{*}{ Patient } & \multirow{2}{*}{$\begin{array}{l}\text { Year of } \\
\text { birth }\end{array}$} & \multirow{2}{*}{$\begin{array}{l}\text { Age at testing } \\
\text { (in years) }\end{array}$} & \multirow{2}{*}{$\begin{array}{l}\text { Education } \\
\text { (in years) }\end{array}$} & \multirow{2}{*}{$\begin{array}{l}\text { WAIS-R } \\
\text { full-scale } \\
\text { IQ }\end{array}$} & \multicolumn{5}{|l|}{ WMS-R } \\
\hline & & & & & Attention & Verbal & Visual & General & Delay \\
\hline A.B. & 1937 & 59 & 20 & 104 & 87 & 62 & 72 & 54 & $<50$ \\
\hline L.J. & 1937 & 59 & 12 & 98 & 105 & 83 & 60 & 69 & $<50$ \\
\hline E.P. & 1922 & 74 & 12 & 103 & 94 & 57 & 82 & 61 & 56 \\
\hline G.T. & 1936 & 60 & 12 & 92 & 120 & 57 & $<50$ & $<50$ & $<50$ \\
\hline
\end{tabular}

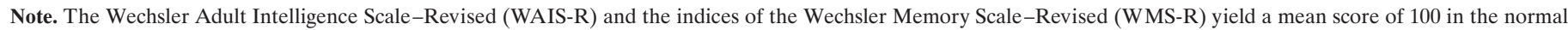
population with a SD of 15. L.J. is female. The other patients are male.

\begin{tabular}{|c|c|c|c|c|c|c|c|c|}
\hline \multirow{2}{*}{$\frac{\text { Patient }}{\text { A.B. }}$} & \multirow{2}{*}{$\begin{array}{l}\begin{array}{l}\text { Diagram } \\
\text { recall }\end{array} \\
4\end{array}$} & \multicolumn{3}{|c|}{ Paired associates } & \multirow{2}{*}{$\begin{array}{l}\text { Word } \\
\text { recall }(\%) \\
33\end{array}$} & \multirow{2}{*}{$\begin{array}{l}\text { Word } \\
\text { recognition }(\%) \\
82.7\end{array}$} & \multirow{2}{*}{$\begin{array}{l}\text { Words } \\
(50)\end{array}$} & \multirow{2}{*}{$\begin{array}{l}\text { Faces } \\
(50) \\
33\end{array}$} \\
\hline & & 1 & 1 & 1 & & & & \\
\hline L.J. & 3 & 0 & 0 & 0 & 40 & 84.7 & 33 & 29 \\
\hline E.P. & 0 & 0 & 0 & 0 & 24 & 65.3 & 24 & 28 \\
\hline G.T. & 0 & 0 & 0 & 0 & 20 & 70.0 & $27^{a}$ & $27^{a}$ \\
\hline \multicolumn{9}{|c|}{ Control means $(n=8)$} \\
\hline & 20.6 & 6.0 & 7.6 & 8.9 & 71 & 97.0 & 41.1 & 38.1 \\
\hline
\end{tabular}

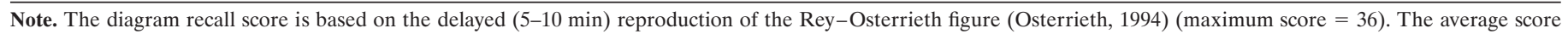

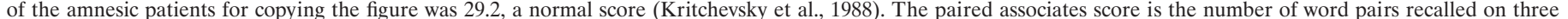

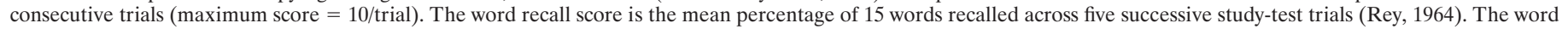

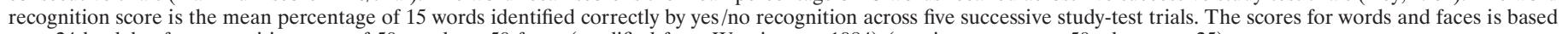
on a $24 \mathrm{hr}$ delay for recognition tests of 50 words or 50 faces (modified from Warrington, 1984) (maximum score $=50$; chance $=25$ ).

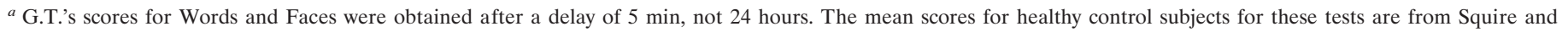
Shimamura (1986).

a number of anterograde and retrograde memory tests, including tests of factual knowledge and tests of autobiographical memory. The findings support the idea that damage to the hippocampal formation produces limited RA and that additional temporal cortical damage is needed to produce severe and extensive RA. Fact knowledge and autobiographical memory were affected similarly overall.

\section{MATERIALS AND METHODS}

\section{Subjects}

Amnesic patients. Four amnesic patients were studied, three men (A.B., E.P., and G.T.) and one woman (L.J.) (Tables 1,2). Two patients (A.B. and L.J.) have damage apparently limited to the hippocampal formation. Patient A.B. became amnesic after a cardiac arrest in 1976. A physician friend and his wife, a nurse, were with A.B. at the time of his arrest and were able to administer resuscitation (CPR) immediately. He arrived at the hospital within $30 \mathrm{~min}$, at which time he was in ventricular fibrillation and having generalized seizures. After treatment, he was breathing spontaneously and maintaining good levels of blood oxygen with minimal supplementation. Seizure activity ceased after the second hospital day, but he remained comatose for the next $8 \mathrm{~d}$. Neurological examination in 1978 indicated mildly impaired cerebellar function, but examinations in 1987 and 1998 found no cerebellar or Parkinsonian signs. On the basis of these findings and the etiology of his amnesia, A.B. is presumed to have circumscribed hippocampal formation damage. This cannot be confirmed with MRI, however, because he wears a pacemaker.

For patient L.J., MRI (Squire et al., 1990) identified that the hippocampal region (subtended by the fimbria, dentate gyrus, hippocampus proper, and subiculum) was reduced in size (left side, $0.37 \mathrm{~cm}^{2}$; right side, $0.42 \mathrm{~cm}^{2}$; six control subjects averaged $0.56 \mathrm{~cm}^{2}$ on the left and 0.63 $\mathrm{cm}^{2}$ on the right) (Fig. 1A). Likewise, the size of the hippocampal formation was reduced when its area was calculated as a percentage of the size of the temporal lobe (left side, $3.23 \%$; right side, $3.38 \%$; six controls averaged $5.02 \%$ on the left and $5.34 \%$ on the right). L.J. became amnesic with no known precipitating event during a 6 month period that began in late 1988. Her memory impairment has remained stable since that time. Both A.B. and L.J. have moderately severe and clinically significant amnesia. Neither is capable of independent living.

Two other patients developed profound amnesia after herpes simplex encephalitis (E.P. in 1992 and G.T. in 1990). Both patients have large, radiologically confirmed, bilateral lesions of the temporal lobe that include the hippocampal formation (Squire and Knowlton, 1995; Hamann et al., 1996). E.P.'s damage is primarily medial temporal but also involves the laterally adjacent fusiform gyrus at some levels. G.T.'s damage is more extensive and involves much of the temporal lobe bilaterally (Fig. $1 B, C)$.

Neuropsychological data for the four patients are presented in Tables 1 and 2 and in Figure 2. Note that all four patients exhibit amnesia despite obtaining intelligence scores within the normal range. Note also that the two postencephalitic patients who have more extensive lesions also have more severe anterograde memory impairment.

Control subjects. Two groups of control subjects were recruited from volunteers and employees at the San Diego Veterans Affairs Medical Center. One group consisted of nine individuals, five matched to patient A.B. and four to L.J. As a group they averaged 62.3 years of age and 15.9 years of education. They scored 22.4 and 52.6, respectively, on the Information and Vocabulary subscales of the Wechsler Adult Intelligence Scale-Revised (WAIS-R) (22 and 57.5 for the patients).

Four additional individuals with a mean of 11.5 years of education served as controls for the postencephalitic patients, E.P. and G.T. Because the two patients differ by 14 years in age, these control subjects were selected to match the older patient (E.P., age 74 years) with respect to age (mean, 73 years). By matching the age of this group to the older patient, we expected to obtain a conservative measure of normal memory performance.

\section{Retrograde memory tests}

New vocabulary (recall and recognition). Subjects completed a vocabulary test involving 82 words that had entered into common English usage between 1955 and $1989(1955-1959, n=12 ; 1960-1969, n=24 ; 1970$ $1979, n=24 ; 1980-1989, n=22$ ) (Verfaellie et al., 1996). Twelve additional common words (e.g., tuxedo, moron) were included to assess baseline vocabulary ability. A recall test was given first in which each word (e.g., zilch) was presented, and the subjects were asked to provide 
Figure 1. Magnetic resonance images for three of the four amnesic patients. For L. J. $(A)$, a coronal T-1 weighted image is shown through the midlevel of the hippocampal formation. The area of her hippocampal formation bilaterally is $66 \%$ of the area calculated for six control subjects and well outside the control range. For E.P. $(B)$, an axial T-2 weighted image through the temporal lobe shows the extent of bilateral medial temporal lobe damage, which extends caudally from the temporal pole and damages bilaterally the perirhinal cortex, the entorhinal cortex, the parahippocampal cortex, the amygdaloid complex, and the hippocampal region (CA fields, dentate gyrus, and subicular complex). The lesion extends laterally to include the fusiform gyrus at some levels, and small foci of damage are apparent in the right medial and dorsal frontal cortex. Finally, reduced volume of the insular cortex and inferotemporal gyrus is apparent bilaterally, although it is unclear how abnormal a finding this is or what implications it has for neuropathology. For G.T. $(C)$, an axial T-2 weighted image through the temporal lobe shows the damage extending through the anterior $7.0 \mathrm{~cm}$ of his left temporal lobe and through the anterior $5.0 \mathrm{~cm}$ of his right temporal lobe. The lesion includes bilaterally the amygdaloid complex, hippocampus, entorhinal, perirhinal, and parahippocampal cortices as well as the inferior, middle, and superior temporal gyri. There is also bilateral damage in the insular cortex, medial and orbital frontal cortex, and cingulate gyrus. Asterisks in $A$ indicate the position of the hippocampus on each side.

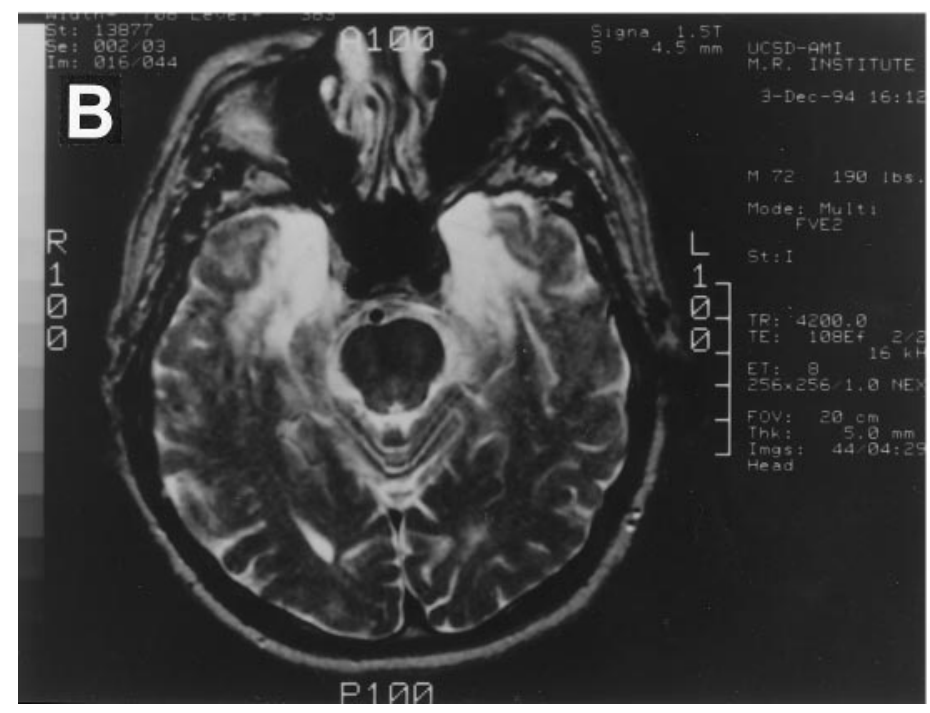

a definition. Responses were scored as either "correct" or "incorrect." Immediately after recall, subjects completed a four-alternative multiple choice form of the same test (e.g., zilch: to destroy or eliminate; a stain; a filmy residue; zero or nothing).

Public events (recall and recognition). The test consisted of 145 questions about public events that had occurred from 1940 through 1995 (1940s, $n=19 ; 1950 \mathrm{~s}, n=17 ; 1960 \mathrm{~s}, n=24 ; 1970 \mathrm{~s}, n=27$; 1980s, $n=$ 30; 1990s, $n=28$ ) (Squire, 1975; Squire et al., 1989). The test was administered first in a recall format (e.g., Who killed John Lennon?), and immediately afterward in a four-alternative multiple choice format (John Hinkley, Sara Jane Moore, David Roth, Mark Chapman).

Famous faces (recall and recognition). Subjects were asked to identify 141 photographs of famous people who came into the news in one of the decades from 1940 to 1995 (1940s, $n=24 ; 1950 \mathrm{~s}, n=27$; 1960s, $n=27$; 1970s, $n=27 ; 1980 \mathrm{~s}, n=24 ; 1990 \mathrm{~s}, n=12$ ) (Albert et al., 1979; Squire et al., 1989). The test was administered first in a recall format in which subjects were presented with each photograph and asked to name the person (e.g., Marilyn Monroe). After the recall test was completed, the subjects were shown each unrecalled photograph and asked either a yes or no question [e.g., Is this person's name Marilyn Monroe? (One-half of the time, the name that was presented was correct.)] or a threealternative multiple choice question (e.g., Which of the following is the name of this person? Gwen Verdon, Brigitte Bardot, or Marilyn Monroe). The recognition score was based on the number of items that were recalled correctly plus the items that were recognized correctly. Note that chance performance on the recognition test was $41.6 \%$ (the average of $50 \%$ and $33.3 \%$ ).

Famous names completion and famous names recognition. For the completion test, the subjects were given a list of 65 items, each consisting of a first name together with the first few letters of a last name (e.g.,
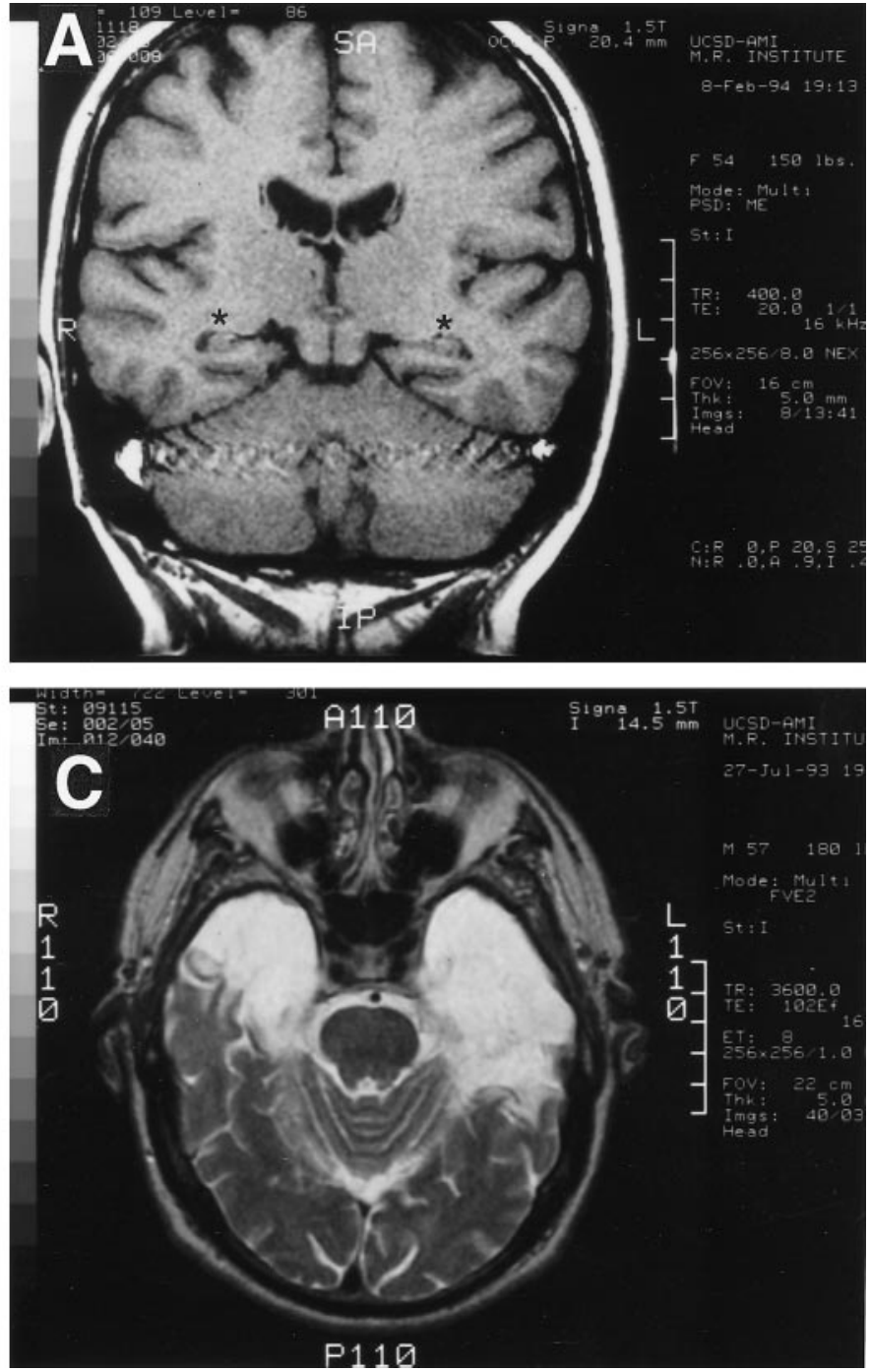

Alfred Hitch ). In each case they attempted to complete the item to form the name of a famous person. All of the correct completions corresponded to names of faces that had appeared on the Famous Faces test $(1940 \mathrm{~s}, n=11 ; 1950 \mathrm{~s}, n=13 ; 1960 \mathrm{~s}, n=11 ; 1970 \mathrm{~s}, n=13 ; 1980 \mathrm{~s}$, $n=11 ; 1990 \mathrm{~s}, n=6)$. For the recognition test, 70 test items were constructed, each consisting of three names (e.g., Joseph Silva, Jimmy Hoffa, Willie Turman). Subjects circled the name that they thought was the name of a famous person. The correct answers for the recognition test also corresponded to the names of faces from the Famous Faces test (1940s, $n=12 ; 1950 \mathrm{~s}, n=13 ; 1960 \mathrm{~s}, n=13 ; 1970 \mathrm{~s}, n=14 ; 1980 \mathrm{~s}, n=$ $12 ; 1990 \mathrm{~s}, n=6$ ). There was no overlap in the items used for the completion test and the recognition test. The Famous Names tests were administered from 1 to 12 weeks after subjects had completed the Famous Faces test.

Autobiographical memory interview (AMI). The AMI (Kopelman et al, 1989 ) is a structured interview that asks subjects to provide detailed information concerning three periods of their lives (i.e., Childhood, Early Adult Life, and Recent Life). Within each of these periods memory was tested for both personal semantic knowledge (e.g., What was your home address while attending high school?) and autobiographical memory (e.g., Describe an incident that occurred while you were attending elementary school.). The portion of the test that assessed personal semantic knowledge consisted of 41 items (Childhood, $n=12$; Early Adult Life, $n=16$; Recent Life, $n=13$ ), and the maximal possible score for each time period was 21. The portion of the test that assessed autobiographical memory consisted of nine items (three per time period), and the maximum score was 9 for each time period (maximum 3 points per item, $0-3$ scoring scale). For each amnesic patient, the accuracy of all responses was established in interviews with at least two family members whose combined familiarity with the patient spanned virtually 

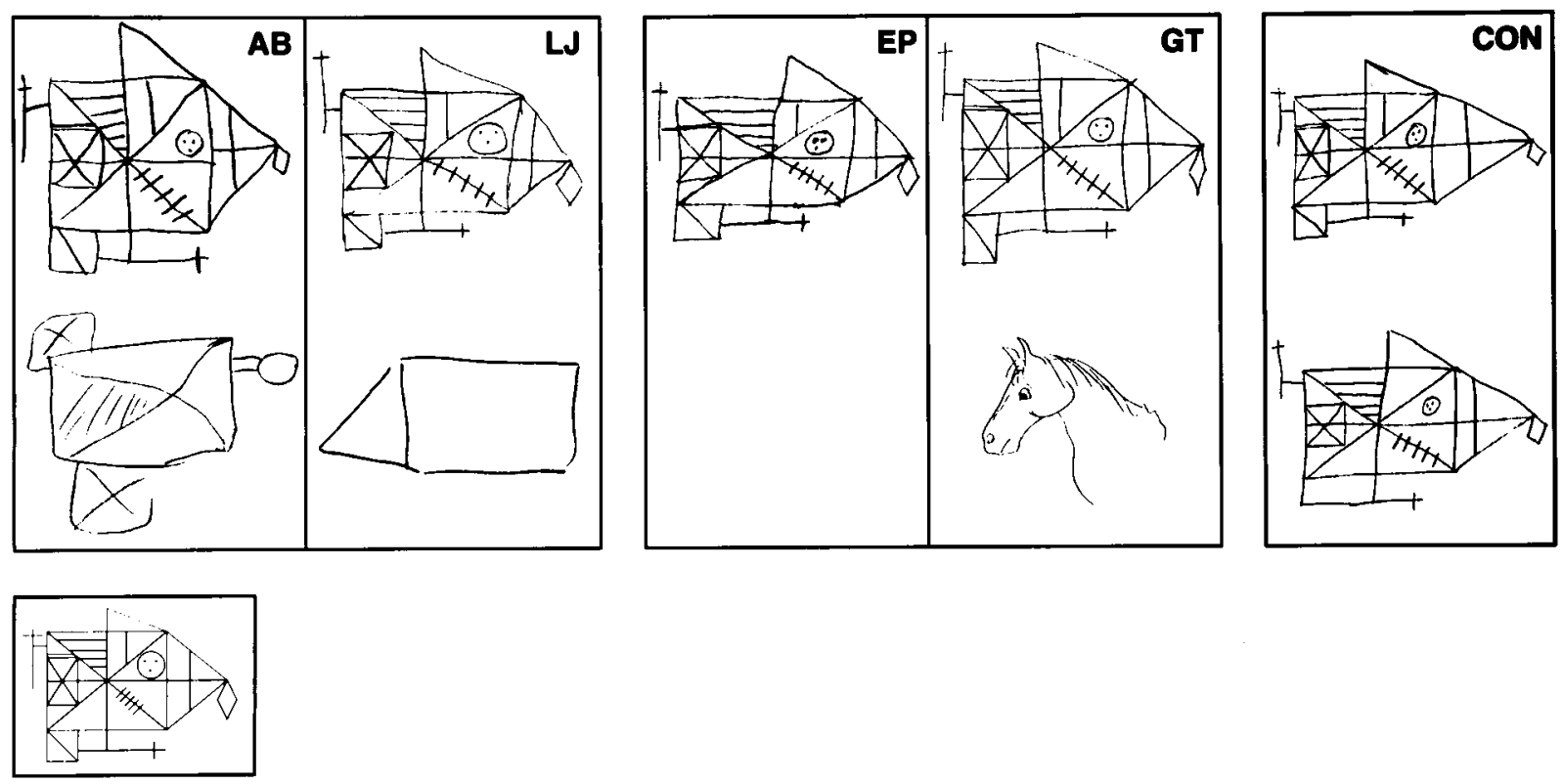

Figure 2. The Rey-Osterrieth figure. Patients were asked to copy the figure illustrated in the small box to the bottom left and, 5-10 min later, to reproduce it from memory. The copy (top) and the reproduction (bottom) are shown from left to right for the four patients and for a representative control subject $(C O N)$. Neither E.P. nor G.T. recalled copying the figure. Encouraged to draw whatever came to mind, patient E.P. declined to try and G.T. produced a drawing of a horse's head.

his/her entire lifetime. Responses were assigned a zero score if any family member identified it as inaccurate.

Word association test of autobiographical memory. A set of 48 common nouns (e.g., dog, water, school) was used to elicit autobiographical memories, using methods described previously (Crovitz and Schiffman, 1974; MacKinnon and Squire, 1989). The words were read aloud one at a time, and the subjects were asked to recollect an autobiographical episode that could be associated with each word. When a subject failed to provide a memory that was clearly specific to time and place, probes were given to elicit the fullest possible response. Probing was done in two ways: (1) encouragement was given to be more specific about an already stated memory, and (2) if a subject could not produce any episode, concrete possibilities were suggested to help the subject recall one. When subjects reported a memory that they had already described in response to a previous cue word, they were asked to recollect a different memory. Finally, when a subject did describe a specific incident, he or she was asked to estimate its date.

Twenty-four cue words were used to assess the remote time period, and 12 cue words each were used to assess the recent and middle time periods. The years defining each time period were determined individually for each subject. For the amnesic patients, the years of their life before they became amnesic were partitioned into three approximately equal-sized time periods (Recent, Middle, Remote). Only four control subjects were tested (those matched to E.P. and G.T.), and their Recent, Middle, and Remote time periods were defined as three equal-sized periods covering their entire lives.

For each subject the testing required 4-10 sessions, each lasting 1-2.5 hr. An index card displaying the first and last year of the time period of interest was in the subject's view at all times. The first 36 of the 48 cue words were used to probe all three periods. Four words were used to probe one time period, then four more were used to probe another time period, and so on until each of the three time periods had been probed with 12 cue words each. All subjects were tested with the same order of words and the same order of time periods. The final 12 cue words were used to probe only the Remote time period. Testing sessions were tape recorded for later scoring by two independent raters. The correlation between their scores was 0.94 . Recollections were rated on a $0-3$ scale, as described previously (Zola-Morgan et al., 1983), and the average of the two raters' scores was used as the score for the response to each cue word. For each amnesic patient the accuracy of all responses was established in interviews with at least two family members whose combined familiarity with the patient spanned virtually his/her entire lifetime.

Information and vocabulary subscales and Boston Naming Test. To evaluate the possible impact on our Remote memory tests of anomia and pervasive loss of general knowledge, we administered the Information and Vocabulary subscales of the WAIS-R NI (WAIS-R as a Neuropsychological Instrument; Kaplan et al., 1991). These subscales are identical in the WAIS-R and the WAIS-R NI except that the WAIS-R NI includes multiple choice (recognition) versions of all of the test items. Finally, we administered the Boston Naming Test both in its standard format (Kaplan et al., 1983) and in a four-alternative multiple choice format. All testing was done in 1996.

Data analysis. Because the patients all became amnesic in a known year, it was possible to assess each patient's anterograde and retrograde memory function separately and then average together the scores from appropriate time periods to obtain group means (Table 3). Test items from the decade (L.J., E.P., and G.T.) or three decades (A.B.) after the onset of their amnesia were taken to measure anterograde amnesia. RA was estimated by using test items that covered either the three decades (A.B. and L.J.) or the four decades (E.P. and G.T.) preceding the onset of amnesia. Scores from items that assessed anterograde memory function for each patient were averaged together, and scores from items that assessed retrograde memory function for each patient were averaged together. The test scores of control subjects (five matched to A.B., four matched to L.J., and four matched to E.P. and G.T.) were assigned to anterograde and retrograde time periods in the same manner as the scores of the patients to whom they were matched.

Given the small number of patients that we have studied, it should be noted that the statistical methods we have used necessarily have low power. Because of this limitation, we occasionally have pointed out certain qualitative features of the data. Thus, it will be important to confirm these findings with additional patients as they become available.

\section{RESULTS}

\section{Patients with hippocampal formation lesions}

The mean scores of A.B. and L.J., the two patients with hippocampal formation lesions, and their controls on eight tests are presented in Figure 3. On the New Vocabulary recall test, the patients performed well on the baseline items (patients, 91.7\% correct; controls, $91.7 \%$ correct). On the recognition version, each patient missed one item, and the control subjects made no errors. The data from the two New Vocabulary tests in Figure 3 were submitted to a 2 (group) $\times 3$ (time period) ANOVA, and 
Table 3. Assessing anterograde and retrograde amnesia

\begin{tabular}{|c|c|c|c|c|c|c|c|c|}
\hline \multirow[b]{2}{*}{ Patient } & \multirow{2}{*}{$\begin{array}{l}\text { Etiology of } \\
\text { amnesia }\end{array}$} & \multirow{2}{*}{$\begin{array}{l}\text { Onset of } \\
\text { amnesia }\end{array}$} & \multirow{2}{*}{$\begin{array}{l}\text { Duration of am- } \\
\text { nesia in years }\end{array}$} & \multirow[b]{2}{*}{$\mathrm{AA}$} & \multicolumn{4}{|c|}{ Years of RA } \\
\hline & & & & & $1-10$ & $11-20$ & $21-30$ & $31-40$ \\
\hline A.B. & Anoxia & 1976 & 20 & $1970-90$ s & $1960 \mathrm{~s}$ & $1950 \mathrm{~s}$ & $1940 \mathrm{~s}$ & - \\
\hline L.J. & Unknown & 1988 & 8 & $1990 \mathrm{~s}$ & $1980 \mathrm{~s}$ & $1970 \mathrm{~s}$ & $1960 \mathrm{~s}$ & - \\
\hline E.P. & Encephalitis & 1992 & 4 & $1990 \mathrm{~s}$ & $1980 \mathrm{~s}$ & $1970 \mathrm{~s}$ & $1960 \mathrm{~s}$ & $1950 \mathrm{~s}$ \\
\hline G.T. & Encephalitis & 1990 & 6 & $1990 \mathrm{~s}$ & $1980 \mathrm{~s}$ & $1970 \mathrm{~s}$ & $1960 \mathrm{~s}$ & $1950 \mathrm{~s}$ \\
\hline
\end{tabular}

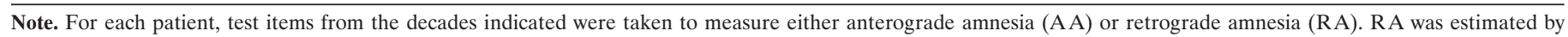
using test items that covered either the three decades (A.B. and L. J.) or the four decades (E.P. and G.T.) preceding the onset of amnesia.

the data from the other six tests in Figure 3 were submitted to a 2 (group) $\times 4$ (time period) ANOVA. There was an interaction of group $\times$ time period for the Famous Faces recognition test, with $F_{(3,27)}=2.97$ and $p<0.05$, but there were no other significant findings, with $F$ values $<2.3$ and $p$ values $>0.10$. Individual $t$ tests at each time period of each test also revealed no significant group differences, with $t$ values $<2.0$ and $p$ values $>$ 0.07. Nevertheless, on six of the eight tests the amnesic patients performed numerically more poorly than the control subjects for the period after they became amnesic, reflecting their anterograde memory impairment. In contrast, for the period before they became amnesic, they performed similarly overall to the control subjects except on the Public Events Recognition test.

To examine this pattern in the data further, we calculated each subject's median percentage correct score across all eight tests. Then the mean of these median scores was calculated for each group (Fig. 4). A 2 (group) $\times 4$ (time period) ANOVA revealed no group effect $\left(F_{(1,9)}=2.27 ; p>0.15\right)$ but did reveal an interaction that approached statistical significance $\left(F_{(3,27)}=2.6\right.$; $p=0.07)$. Further analysis of these data indicated that the amnesic patients were impaired significantly on items from their period of anterograde amnesia, with $t(9)=2.28$ and $p<0.05$. Both patients exhibited low scores for this time period (A.B., $71.7 \%$; L.J., $72.5 \%$ ). In contrast, they performed about as well as control subjects on items from the three time periods before they became amnesic, with $t$ values $<1.2$ and $p$ values $>0.10$ (A.B., $84.0 \%$; L.J., 78.7\%). This absence of measurable RA should be interpreted cautiously. For the period 1-10 years before amnesia, the mean score for the two patients was numerically below the control mean on five of the eight tests. It is therefore possible that some RA was present. If so, it was temporally limited and spanned $<10$ years.

Performance on the AMI is shown in Figure 5. For the items assessing personal semantic knowledge, A.B. and L.J. scored overall approximately as well as control subjects. Note that 11 of the 13 items from the Recent Life time period inquired about the period of anterograde amnesia. A 2 (group) $\times 3$ (time period) ANOVA revealed no significant effects, with $F$ values $<1.1$ and $p$ values $>0.10$. Examination of the individual data indicated that the patients generally performed well within the normal range at each of the three time periods. The single exception was that A.B. scored just below the lowest-scoring control subject on items from the Recent Life time period. All of L.J.'s responses could be verified as accurate by family members. Patient A.B. provided inaccurate responses to two items from the Recent Life time period, and his score was adjusted from 19 to 17 points. His other responses were verified as accurate.

For autobiographical memory, A.B. and L.J. performed poorly for the Recent Life time period and well for the two earlier time periods. In the case of autobiographical memory, all three items from the Recent Life time period inquired about the period of anterograde amnesia. A 2 (group) $\times 3$ (time period) ANOVA revealed no significant effects, with $F$ values $<1.7$ and $p$ values $>$ 0.10 . However, separate comparisons indicated that performance was impaired for the Recent Life time period, $t(9)=2.43$ and $p<$ 0.04 , with both patients scoring below all but one control subject. Performance was intact for the other two time periods, with $t$ values $<$ 1.0. All of A.B.'s responses and all but one of L.J.'s responses were verified as accurate. That one response, from her Early Adult time period, could not be classified as accurate or inaccurate by her family.

Performance on the word association test of autobiographical memory is shown in Figure $6 A$. Each recollection was scored by using the 0-3 scale. The amnesic patients provided well formed episodic memories (scores $\geq 2.5$ ) in response to most of the 48 cue words (A.B. and L.J. each provided 40; the four controls averaged 39.5 episodic memories). For patient A.B., 25 of these 40 memories were verified as accurate by family members. The remaining 15 memories could not be identified as accurate or inaccurate. For patient L.J., all autobiographical memories were verified as accurate by family members. In the analyses that follow, we included all of the patients' recollections, except those identified as inaccurate. When we also excluded recollections that could not be identified as either accurate or inaccurate, the results were the same.

A 2 (group) $\times 3$ (retrograde time period) ANOVA revealed no significant effects; all $F$ values were $<0.8$ (Fig. $6 A$ ). Examination of the individual data indicated that the patients generally performed well within the normal range. The single exception was that A.B. scored below the lowest-scoring control subject for the Recent Life retrograde time period (mean, 2.58 for A.B.; mean, 2.75 for the lowest-scoring control subject). It is also of interest that, of the 10 recollections that he successfully produced from the Recent Life retrograde time period (maximum, 12), nine of them were from the earliest three years of that period, 10-13 years before he became amnesic. Thus, A.B. exhibited evidence of $\sim 10$ years of RA for autobiographical memory.

For each well formed autobiographical memory (scores $\geq 2.5$ ), we also counted the number of prompts required before obtaining a successful episodic narrative (Fig. 6B). Patient A.B. required more prompts than control subjects for the Recent Life (mean, 5.1 for A.B.; mean, 1.1 for controls) and the Middle (mean, 4.4 for A.B.; mean, 1.1 for controls) retrograde time periods but was within the range of controls for the Remote time period. Patient L.J. required more prompts than did the controls for the Middle retrograde time period (mean, 4.2 for L.J.; mean, 1.1 for controls) but was within the range of controls for the Recent Life and Remote time periods.

We next calculated the time that elapsed between the presentation of a cue word and the initiation of an episodic narrative 

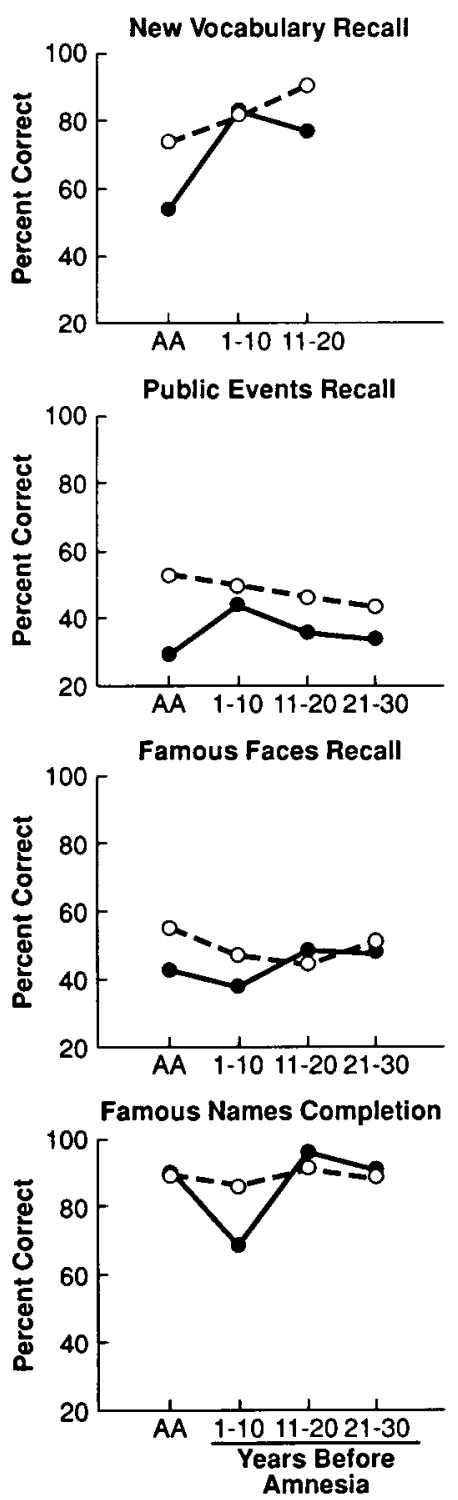
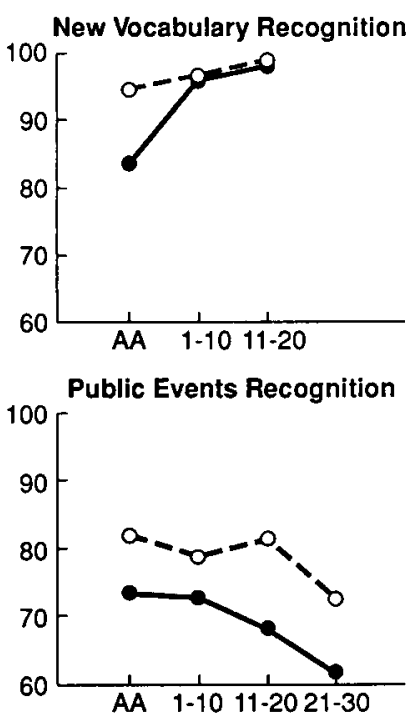

Famous Faces Recognition

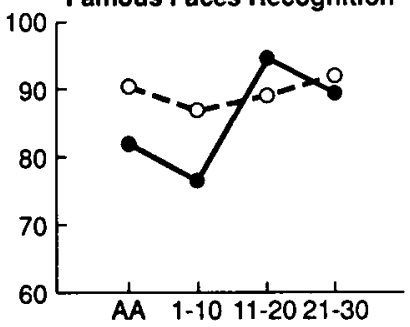

Famous Names Recognition

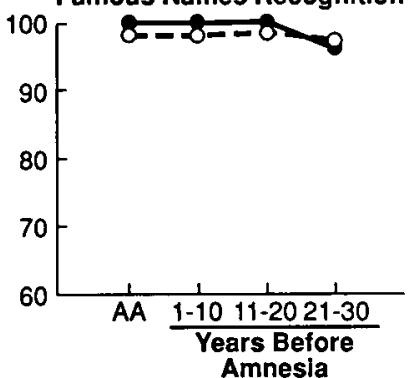

Figure 3. Performance of two amnesic patients (A.B. and L.J.) with lesions of the hippocampal formation (-) and nine control subjects $(\bigcirc-\bigcirc)$ on tests of fact knowledge. Anterograde amnesia $(A A)$ was measured by performance on test items covering the period from 1970 to 1995 (for A.B.) and from 1990 to 1995 (for L.J.). Retrograde amnesia (RA) was measured by performance on test items covering the period from 1940 to 1969 (for A.B.) and from 1960 to 1989 (for L. J.). For their control subjects, test items were assigned to AA and RA time periods in the same way, i.e., the data for five subjects were partitioned to match A.B., and the data for four subjects were partitioned to match L.J. Performance on tests of recall is presented on the left, and performance on recognition tests is presented on the right. Chance levels of performance on the recognition tests were $25 \%, 25 \%, 41.2 \%$, and $33.3 \%$ for the New Vocabulary, Public Events, Famous Faces, and Famous Names tests, respectively.

(Fig. 6C). Compared with control subjects, patient A.B. was slower to initiate episodic narratives for all time periods. Patient L.J. performed similarly to control subjects but was a little slower than control subjects for the Middle time period. A.B.'s marked slowness in producing well formed recollections is in accord with our experience over the years. He is generally slow at motor and cognitive tasks. Thus, slowness is a feature of his behavior since

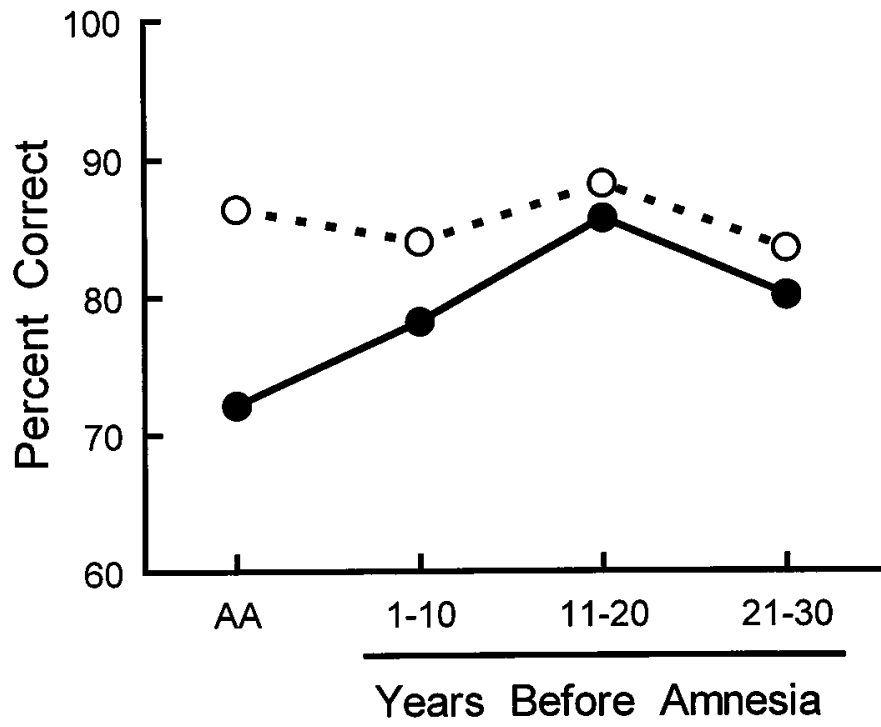

Figure 4. Performance of the two patients (A.B. and L.J.) with hippocampal formation lesions $(-\bigcirc)$ and their controls $(\bigcirc-\bigcirc)$ on all eight tests of fact knowledge listed in Figure 3. The scores are group means that are based on each subject's median score for the eight tests.
Personal Semantic Memory

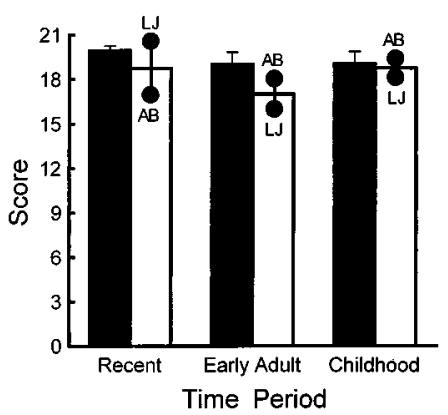

Autobiographical Memory

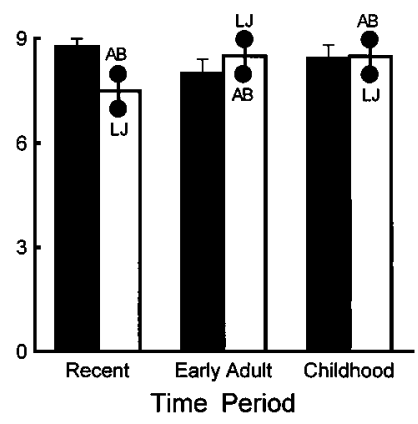

Figure 5. Performance of two amnesic patients with lesions of the hippocampal formation (open bars) and control subjects ( filled bars; $n=$ 9) on the Autobiographical Memory Interview (AMI). Scores for items that assessed memory for Personal Semantic knowledge (maximum, 21) are presented on the left, and scores for items that assessed Autobiographical Memory (maximum, 9) are presented on the right. Eleven of the 13 test items from the Recent time period assessed memory for information that patients could have acquired only subsequent to the onset of their amnesia. Accordingly, these scores reflect primarily anterograde amnesia. The scores from the other two time periods reflect retrograde memory function. Error bars indicate the SEM for control subjects. Individual scores for each patient are identified by their initials.

the onset of his amnesia; it does not reflect a specific problem retrieving autobiographical memories.

To assess the autobiographical recollections qualitatively, we scored the content of each memory on the basis of previously described methods (Johnson et al., 1988, 1997) (Fig. 7). Each well formed autobiographical memory (a score of $\geq 2.5$ ) was scored for the amount of detail that subjects provided in 10 different categories (people, places, actions, objects, spatial, emotional, temporal, sensory-perceptual, cognitive, and factual/background). The frequency with which each memory included details about each of these characteristics was rated on a seven-point scale $(1=\mathrm{min}-$ imal detail; $7=$ maximal detail). In previous studies such rating procedures have distinguished between memory for real and 

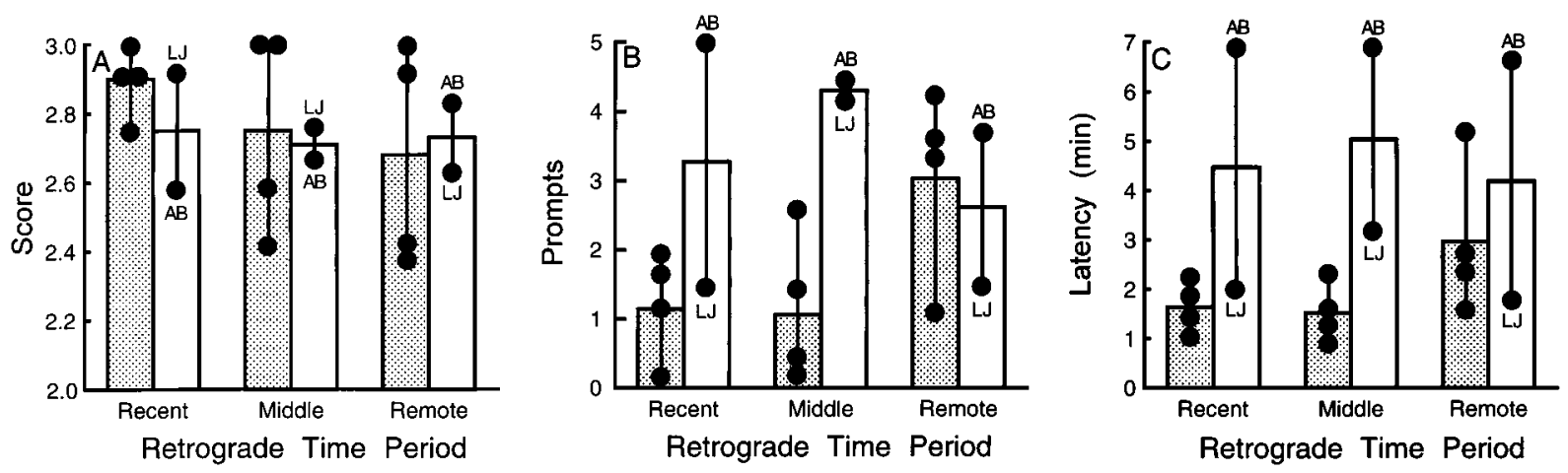

Figure 6. Performance of the two amnesic patients with lesions limited to the hippocampal formation (open bars) and four control subjects (shaded bars) on the word association test of autobiographical memory. $A$, Mean episodic memory scores for the three premorbid time periods that assessed retrograde amnesia (based on 12 cue words each for the Recent Life and Middle periods and based on 24 cue words for the Remote period). $B$, The mean number of prompts provided by the experimenter before the initiation of a well formed autobiographical recollection that scored $\geq 2.5$ points. $C$, The mean time between the presentation of a cue word and the initiation of a well formed autobiographical recollection. Filled circles show the scores of each subject.

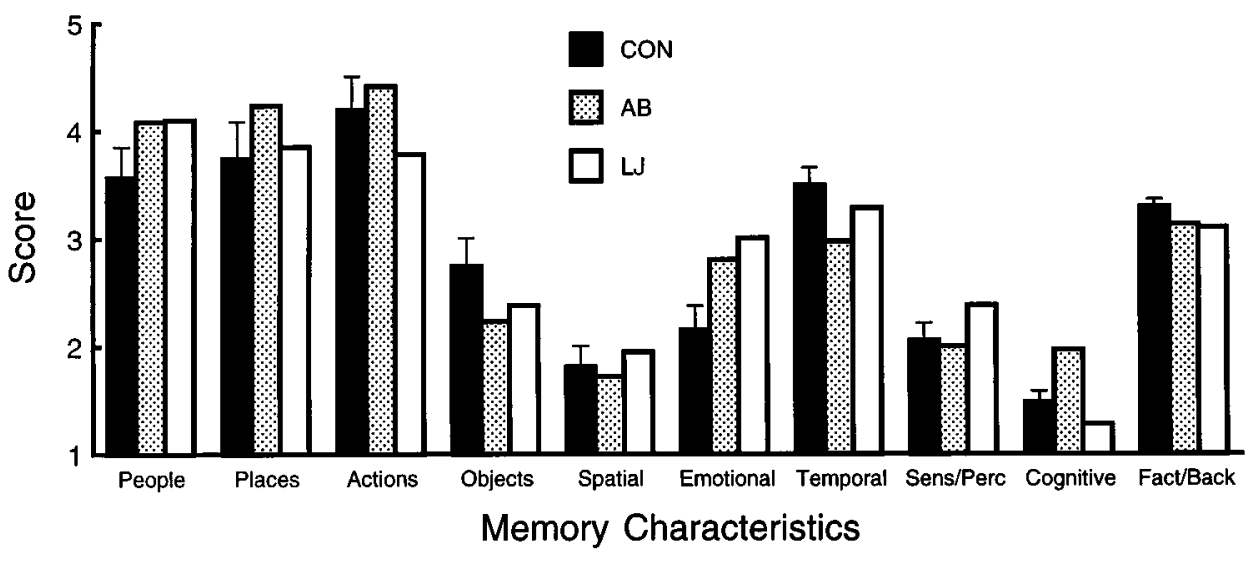

Figure 7. Mean ratings of the amount of detail provided in each autobiographical recollection by patients with lesions limited to the hippocampal formation (A.B., shaded bars; L.J., open bars) and four control subjects ( filled bars). Each memory was rated according to the frequency with which subjects included details related to 10 memory characteristics, using 7 point scales $(1=$ minimal detail; $7=$ maximal detail $)$. Sens/Perc, Sensoryperceptual detail; Fact/Back, factual context and background information. Error bars indicate the SEM for control subjects.

imagined events (Johnson et al., 1988) and between genuine and confabulated memories (Johnson et al., 1997).

A 2 (group) $\times 3$ (retrograde time period) $\times 10$ (memory characteristic) ANOVA revealed a significant effect of memory characteristic, with $F_{(9,36)}=35.46$ and $p<0.001$, indicating that there was a pattern to the content of the recollections. Subjects provided the most amount of detail regarding people, places, and actions and the least amount of detail concerning cognitive, spatial, and sensory-perceptual aspects of their memories. No other effects were significant, with $F$ values $<1.8$ and $p$ values $>$ 0.10 . Thus, the amnesic patients exhibited the same pattern as the control subjects. Indeed, the amnesic patients scored within the range of the control subjects on all 10 memory characteristics.

In summary, A.B. and L.J. exhibited anterograde memory impairment but limited RA. Significant RA for facts could not be detected, and if retrograde memory loss is present, it appears to be temporally limited and covers $<10$ years. A.B. exhibited RA for autobiographical episodes covering approximately the decade before the onset of his amnesia. L.J. did not exhibit detectable RA for autobiographical episodes.

\section{Patients with postencephalitic amnesia}

The mean scores of the two postencephalitic patients and their controls on eight tests are presented in Figure 8. The patients were impaired on both the recall and the recognition versions of the baseline items from the New Vocabulary test $(41.7 \%$ and $62.5 \%$ correct for the patients; $95.9 \%$ and $95.8 \%$ correct for the controls; $p$ values $<0.05)$. Thus, these two patients were impaired in accessing word meanings.

The data from the New Vocabulary tests in Figure 8 were submitted to a 2 (group) $\times 4$ (time period) ANOVA, and the data from the other six tests in Figure 8 were submitted to a 2 (group) $\times 5$ (time period) ANOVA. The patients were impaired severely on every test $(F$ values $>12.0 ; p$ values $<0.03)$. Significant group $\times$ time period interactions were obtained for the New Vocabulary recognition test $\left(F_{(3,12)}=19.4 ; p<0.001\right)$ and for the Famous Names Completion test $\left(F_{(4,16)}=6.18 ; p<0.01\right)$. On five of the eight tests (Public Events Recall and Recognition, Famous Faces Recall and Recognition, and Famous Names Recognition), the patients performed at floor levels across all time periods. When they performed above floor levels, their retrograde memory impairment for knowledge of events and people was similar to their memory impairment for general semantic knowledge (i.e., word meanings).

Performance also was examined by calculating the average performance across the eight tests (Fig. 9), using the same method that was used for the patients with hippocampal formation lesions. The patients were severely impaired $\left(F_{(1,4)}=119.3\right.$; 

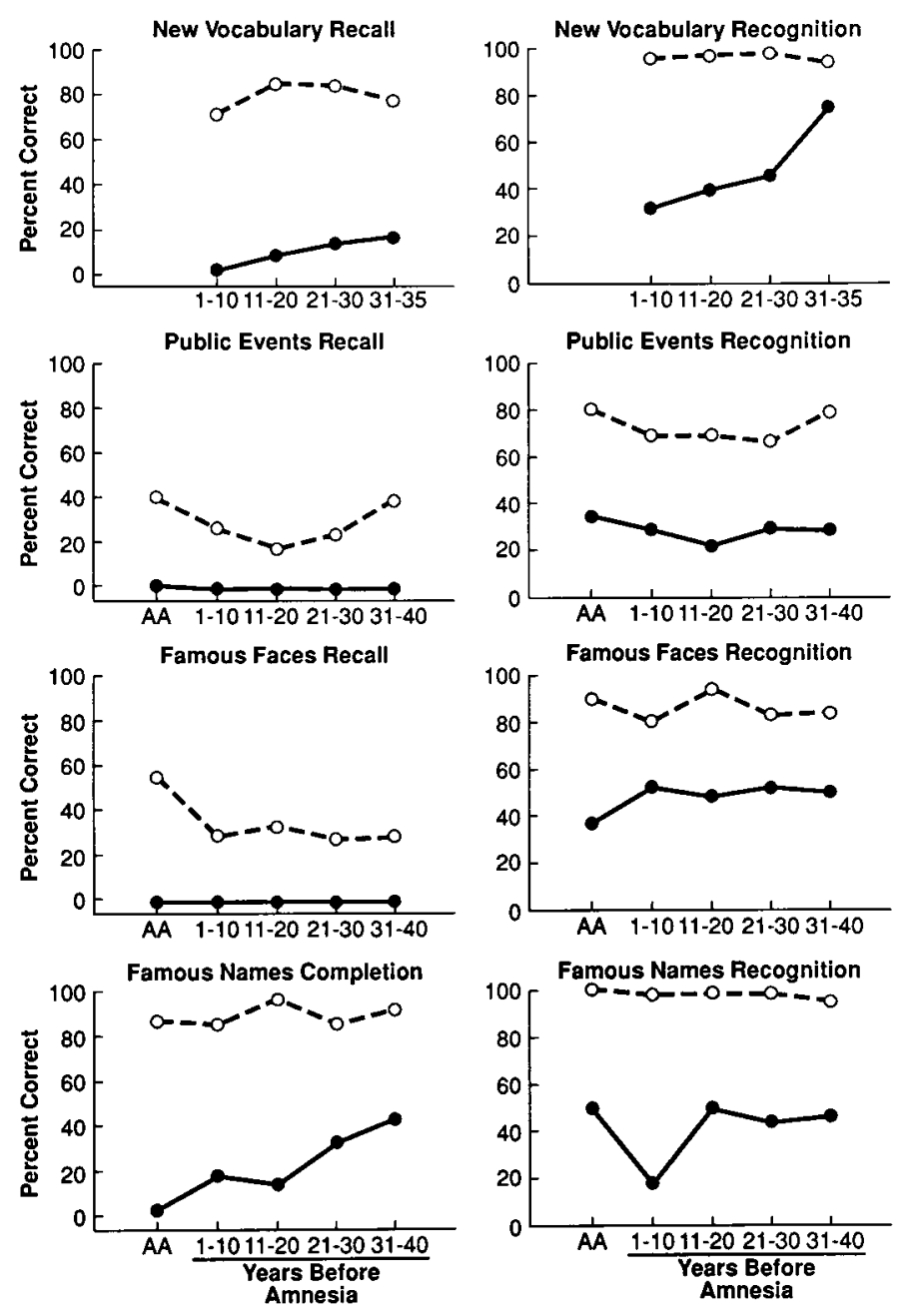

Figure 8. Performance of two postencephalitic amnesic patients $(-\mathbf{0})$ and four control subjects $(\bigcirc-\bigcirc)$ on tests of retrograde memory for semantic knowledge. Anterograde amnesia $(A A)$ was measured by performance on test items covering the period from 1990 to 1995. RA was measured by performance on test items covering the period from 1950 to 1989. The New Vocabulary tests did not include items from the period of anterograde amnesia for patients E.P. and G.T. Performance on tests of recall is presented on the left, and performance on recognition tests is presented on the right. Chance levels of performance on the recognition tests were $25 \%, 25 \%, 41.2 \%$, and $33.3 \%$ for the New Vocabulary, Public Events, Famous Faces, and Famous Names tests, respectively.

$p<0.001)$, and there was no interaction of group $\times$ time period $\left(F_{(4,16)}=2.18 ; p>0.11\right)$. Separate comparisons between groups revealed impaired performance at every time period, with $t$ values $>5.7$ and $p$ values $<0.005$.

Performance on the AMI is shown in Figure 10. With one exception, all of E.P.'s and G.T.'s responses could be verified by family members. The exception was one of E.P.'s autobiographical memories from the Childhood period. Because the two patients performed differently, their scores are considered separately. The very poor performance of E.P. and G.T. (for both personal semantic memory and autobiographical memory) on items from the Recent Life time period is consistent with their severe anterograde memory impairment. They either gave no response or they responded inaccurately, or more commonly they provided information appropriate to earlier time periods. For the Early Adult Life period, personal semantic memory was im-

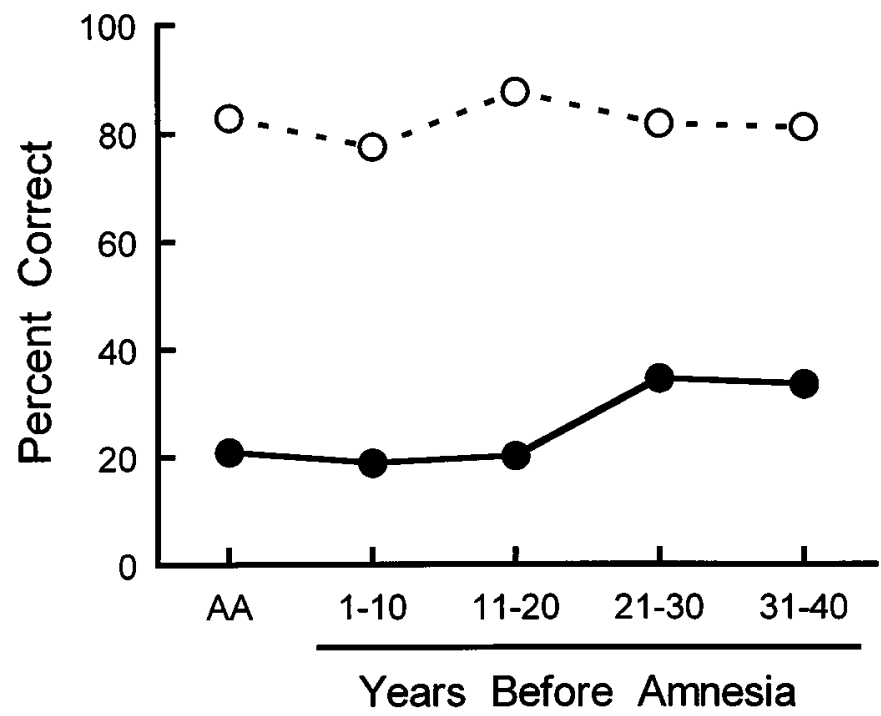

Figure 9. Performance of the two postencephalitic amnesic patients (-) and their controls $(\mathrm{O}-\mathrm{O})$ on all eight tests of RA shown in Figure 6. The scores are group means that are based on each subject's median score for the eight tests.

paired, and the patients each scored $>13$ SD below the control subjects. For autobiographical memory, E.P.'s score for Early Adult Life was at the lower end of the range of control subjects, and G.T. received no points at all. For the Childhood period, E.P.'s performance was normal for both personal semantic memory and autobiographical memory (Table 4). Indeed, he scored nearly as high as the highest-scoring control subject for both tests. In contrast, G.T. was severely impaired on both tests. For personal semantic information, G.T.'s score (5 points) was lower than the score of the lowest-scoring control subject ( 8 points). For autobiographical memory, G.T. received no points for the Childhood period. Thus, E.P. demonstrated sparing of both personal semantic and autobiographical memory from his childhood, whereas G.T. exhibited severe RA across all time periods tested.

A similar pattern of RA for autobiographical events was found with the word association test of autobiographical memory. In response to the 48 cue words, patient E.P. provided only 24 episodic autobiographical memories (ones that scored $\geq 2.5$ ). Four of these were identified as inaccurate by family members. Of the remaining 20 memories, 15 were verified as accurate ( 0 from the Recent Life period, 3 from the Middle period, and 12 from the Remote period). The remaining five memories could not be identified by family members as either accurate or inaccurate.

Patient G.T. provided 18 episodic autobiographical memories, but 10 of these were identified as inaccurate. Of the remaining eight memories, four were identified as accurate (all from the Remote period). The remaining four (two each from the Middle and Remote periods) could not be identified as either accurate or inaccurate.

The scores obtained by E.P. and G.T. on the word association test of autobiographical memory were similar to their scores on the autobiographical portion of the AMI. Patient E.P. performed poorly for the Recent Life and Middle retrograde time periods (scores were 0.8 and 1.7, respectively; compare with Fig. 6A). For the Remote retrograde time period, however, E.P.'s score (2.3) was within $2 \mathrm{SD}$ of the control score (mean, 2.7; $\mathrm{SD}=0.3$ ). Patient G.T. performed poorly in each retrograde time period 
Table 4. Childhood memories described by patient E.P. and a control subject $(\mathrm{CON})$

Describe an incident from the period before you attended school.

E.P.: When I was 5 years old, we moved from Oakland to the country. I was very excited and looked forward to the change. I remember the truck that dad rented. It was hardly full because we didn't have much furniture. When it was time to leave, mom got in the car and followed behind the truck. I rode in the truck with dad.

CON: I remember the day that my older sister started school. I cried because I was the only one who wasn't going. I carried on so much that my mother got fed up and told my sister to take me with her to school. So I ended up starting school early.

Describe an incident that occurred during the period in which you attended elementary school.

E.P.: I was in second grade. I was playing in the schoolyard. I was running, and I tripped and fell. I broke my arm. Mom came and took me to Dr. T. in downtown Hayward. He put a cast on my arm. I wore it for 4 weeks.*

CON: I was playing in the schoolyard-swinging on a pole. The pole came down and hit a third grade girl that was playing nearby. It crushed her and she was out of school for the rest of the year.

Describe an incident that occurred during the period in which you attended high school.

E.P.: When I was 13, I got sick. I got all swollen. Mom drove me to Dr. T.'s office. He said I had dropsy and said I had to stay in bed for a month. I was upset because I couldn't go out and play with my friends. I gave mom urine samples every day. She took them to the doctor's office to check for blood.*

CON: In high school biology class, we took a field trip to the woods. It was during the spring. We went looking for plants to identify them. It was a very pleasant day, pretty and relaxing.

Note. The specific AMI test items are presented, followed by the memories described by patient E.P. and an age-matched control subject who received the same Autobiographical Memory score as E.P. for the Childhood period. The accuracy of two of the memories described by E.P. was verified $(*)$, but family members were unable to confirm or disconfirm the accuracy of the third memory. If one assumes that this memory was inaccurate, E.P.'s score remains within the range of control subjects' scores.

(1.2, 1.5, and 1.5 for the Recent Life, Middle, and Remote time periods, respectively).

For the Remote retrograde time period in which E.P. performed relatively well, the number of prompts required before initiating his recollections (mean, 2.0) was within the range of control subjects (1.1-4.2). In addition, the time needed to initiate his recollections $(2.5 \mathrm{~min})$ was within the range of control subjects (1.6-5.2 min). Finally, E.P.'s 16 memories from the Remote time period were scored for detail according to the same 10 memory characteristics used to evaluate the other patients. E.P. scored within the range of control subjects on all 10 characteristics.

In summary, both E.P. and G.T. exhibited severe and extensive RA for both facts and events. E.P. was able to recall facts and events from his early life (Fig. 10).

\section{Other neuropsychological tests}

Figure 11 shows performance on the Information and Vocabulary subscales of the WAIS-R N I and on the Boston Naming Test. The two patients with hippocampal formation lesions performed identically to the controls on all of the tests ( $t$ values $<1.0 ; p$ values $>$ 0.39). The postencephalitic patients performed differently. E.P.'s scores were within the normal range for both forms of the Information test, but G.T. scored $>2$ SD below control subjects on both forms. E.P. and G.T. also were impaired on both forms of the Vocabulary test, scoring $>3$ SD below the control subjects. This finding is consistent with their impaired baseline performance on the New Vocabulary tests. Finally, E.P. and G.T. both scored $>5$ SD below control subjects on the two forms of the Boston Naming Test. G.T. was more impaired than E.P. on these tests, presumably because his lesion includes much of the temporal lobe, whereas E.P.'s lesion does not extend as far laterally.

\section{DISCUSSION}

\section{Patients with hippocampal formation lesions}

Patients A.B. and L.J. exhibited a discontinuity between premorbid and postmorbid memory. They were impaired at remembering facts and events from the period after they became amnesic but were much better at remembering facts and events from the period before they became amnesic (see Figs. 3, 4, 5, 6). These findings indicate that the brain structures damaged in these two patients are important for establishing new memories about facts and events but are less involved in recollecting memories that already were established several years earlier. This distinction between establishing new memories and recollecting old ones depends on having assessed the postmorbid and premorbid time periods with the same type of test item, as we did in the current study.

\section{Fact learning after hippocampal formation lesions}

Several studies have documented impaired learning of new facts and vocabulary words in amnesic patients with medial temporal lobe lesions (Marslen-Wilson and Teuber, 1975; Schacter et al., 1984; Glisky et al., 1986; Shimamura and Squire, 1987; Gabrieli et al., 1988; Hamann and Squire, 1995). Other studies have reported that patients with medial temporal lobe lesions, in addition to their anterograde amnesia, also have difficulty recollecting factual information from the period before the onset of their amnesia (Corkin, 1984; Beatty et al., 1987; Salmon et al., 1988; Kopelman et al., 1989; Squire et al., 1989; Kartsounis et al., 1995; RempelClower et al., 1996; Schmidtke and Vollmer, 1997).

The findings for A.B. and L.J. are consistent with previous reports in showing deficient acquisition of new factual knowledge about vocabulary, famous people, and public events. These two patients, together with the patient described by Kartsounis and colleagues (1995), appear to be the only instances in which this point has been established for patients with lesions thought to be limited to the hippocampal formation. One other report described three children who sustained hippocampal damage early in life, who nevertheless attended mainstream schools and by the ages of 12-19 had acquired levels of factual knowledge in the low-average to average range (Vargha-Khadem et al., 1997). Because the rate of factual learning that occurred during childhood is unknown, the findings for these three individuals do not contradict the generalization that new fact learning is impaired by hippocampal pathology. Nevertheless, this report and others (Corkin, 1984; Glisky et al., 1986; Hamann and Squire, 1995) emphasize the point that repetition, day after day and across multiple learning opportunities, in the fullness of time can provide amnesic patients with a considerable fund of factual knowledge. The present finding that A.B. and L.J. possess deficient factual knowledge 
Personal Semantic Memory

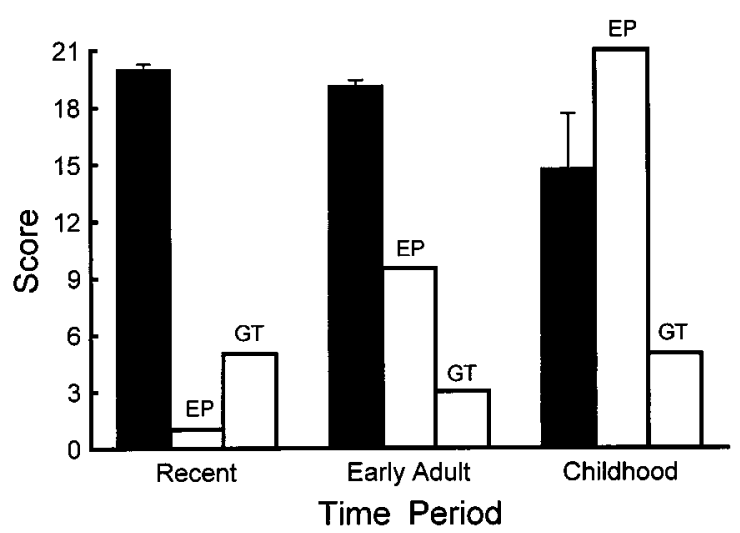

Autobiographical Memory

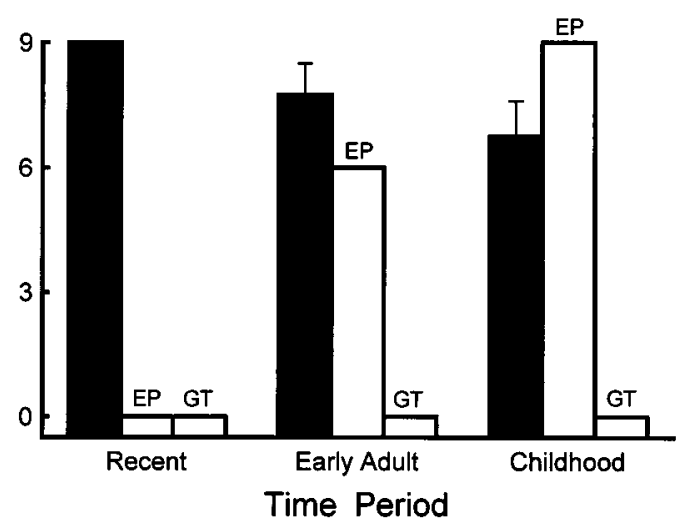

Figure 10. Performance of two postencephalitic amnesic patients (open bars) and control subjects ( filled bars; $n=4$ ) on the Autobiographical Memory Interview (AMI). Scores for items that assessed memory for Personal Semantic knowledge (maximum, 21 for each time period) are presented on the left, and scores for items that assessed memory for Autobiographical Memory (maximum, 9 for each time period) are presented on the right. Test items associated with the Recent time period assessed memory for information that could have been acquired only subsequent to the onset of amnesia. The scores from the other two periods reflect retrograde memory function. For the control subjects, error bars indicate the SEM. The performance of each patient is shown separately.

Information (WAIS-R NI)

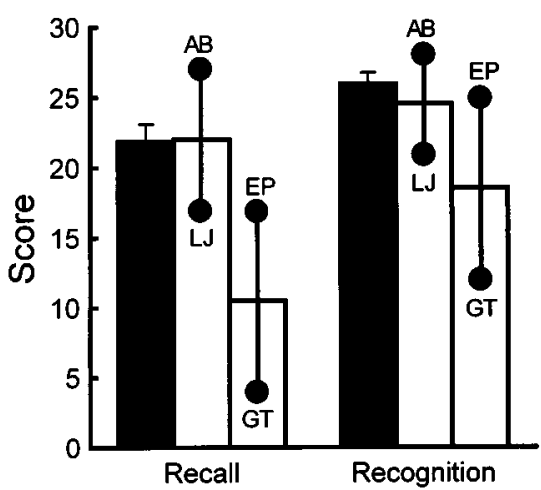

Vocabulary (WAIS-R NI)

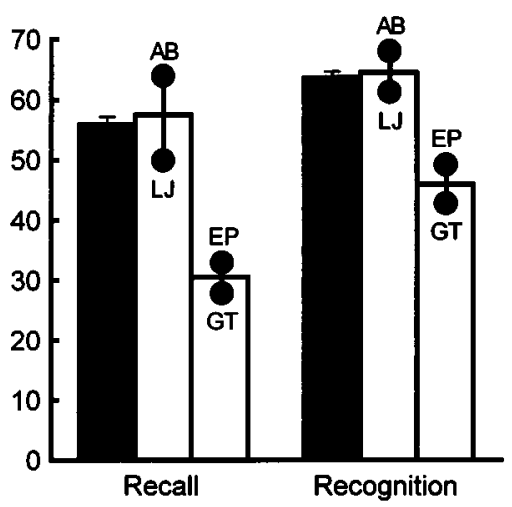

Boston Naming Test

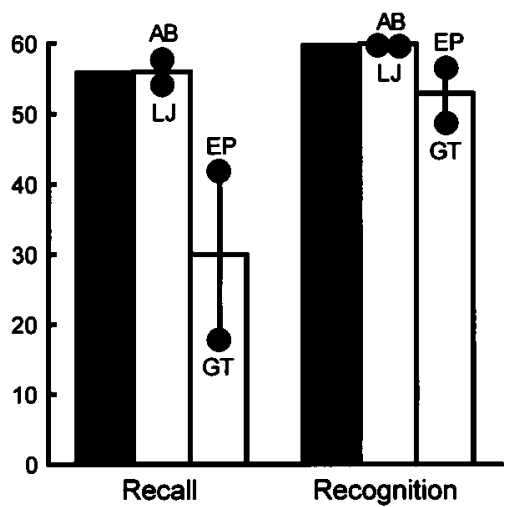

Figure 11. Mean scores of all 13 control subjects ( filled bars), two amnesic patients with lesions of the hippocampal formation (A.B. and L.J.), and two postencephalitic amnesic patients (E.P. and G.T.) on the Information subtest of the Wechsler Adult Intelligence Scale-Revised as a Neuropsychological Instrument (WAIS-R NI), the Vocabulary subtest of the WAIS-R NI, and the Boston Naming Test. Each patient's score is identified by his or her initials. Performance on the recall version of each test is presented on the left side of each panel, and performance on a recognition form of the same test is presented on the right side. The maximum possible scores for the Information subtest, the Vocabulary subtest, and the Boston Naming Test are 29, 70, and 60 , respectively. For the control subjects, error bars indicate the SEM.

about the years since the onset of their amnesia shows that factual knowledge does not accrue inevitably to normal levels in the face of hippocampal pathology.

\section{Event memory after hippocampal formation lesions}

For patients with circumscribed medial temporal lobe lesions, several studies have reported RA for autobiographical material (Kopelman et al., 1989; MacKinnon and Squire, 1989; Victor and Agamanolis, 1990; Kartsounis et al., 1995; Rempel-Clower et al., 1996; Schmidtke and Vollmer, 1997). Some of these studies report a general difficulty in producing autobiographical recollections, and others describe impairments that are limited to the recent postmorbid period. One difficulty with this literature is that it has not been possible in many cases to determine the extent of the lesion or the likelihood that some damage has occurred outside the medial temporal lobe (especially in cortex adjacent to the medial temporal lobe). Another difficulty lies simply in the problem of how to estimate the severity and extent of memory loss for personal events. There are few standardized tests available, and often the recollections cannot be validated. Finally, assessing the quality of autobiographical recollections is beset by the additional problem that anterograde amnesia may impede the reconstruction of a past memory. That is, to the extent that recollecting the past requires an amnesic patient to hold material in working memory while engaging in strategic search, the task of reconstruction might itself depend on anterograde memory function.

In view of these difficulties, the key to understanding similarities and differences in how RA presents itself lies in obtaining as much information as possible about the underlying neuropathology. During the past 15 years four amnesic patients with hippocampal formation lesions came to autopsy, and their brains were examined in considerable neurohistological detail (ZolaMorgan et al., 1986; Rempel-Clower et al., 1996). All of the patients had been evaluated formally with respect to anterograde and RA, using many of the same tests that were given to patients 
A.B. and L.J. Two of the patients (R.B. and G.D.) proved to have bilateral lesions limited to the CA1 field of the hippocampus, and they had a moderate level of anterograde amnesia and RA limited to perhaps a few years at the most. The other two patients (L.M. and W.H.) had lesions involving all of the hippocampal cell fields, the dentate gyrus, and some cell loss in the entorhinal cortex (as well as subicular damage for W.H.). L.M. had moderate anterograde amnesia and an estimated 15 years of RA. W.H. had severe anterograde amnesia and as many as 25 years of RA. The findings for A.B. and L.J. would appear to place them intermediate in severity between R.B. and G.D. on the one hand, and L.M. and W.H. on the other.

In the context of these findings, it is useful to consider another patient who had abnormal MRI signals in the CA1 and CA2 fields after a seizure and who was poor at producing autobiographical recollections from virtually every period of his adult life (Kartsounis et al., 1995). Considering that this patient had a history of heavy drinking, pulmonary disease, and a history of cerebral ischemia and seizures, it seems unlikely that his damage could be limited to the CA fields of the hippocampus. Postmortem histological analysis will be important in this case to determine the areas of damage.

Although histological information is not available for the two patients reported here (A.B. and L.J.), it is noteworthy that they also were capable of accurate autobiographical recollections. Moreover, the recollections of these two patients exhibited the same pattern of characteristics as the recollections of control subjects (see Fig. 7). These findings count against the suggestion that the hippocampal formation is needed to retrieve autobiographical memories throughout life (Nadel and Moscovitch, 1997). The available data would appear to favor an earlier idea (Cohen and Squire, 1981), recently articulated by Verfaellie and colleagues (1995): “. . learning of any kind, whether it be episodic or semantic, may be more impaired in amnesia when information was acquired recently rather than remotely" ( $p$ 451).

\section{Patients with postencephalitic amnesia}

The findings for these two patients are similar in some respects to previous reports of extensive, "flat" gradients of RA in postencephalitic amnesia [patient S.S., Cermak and O'Connor (1983); patient D.R.B., Damasio et al. (1985); and patient R.F.R., Warrington and McCarthy (1988)]. Extensive remote memory impairment also has been described after temporal lobectomy (Barr et al., 1990; Warrington and Duchen, 1992) or temporal lobe infarction (Schnider et al., 1994). In virtually all of these cases, as well as in patient G.T., there is evidence of lateral temporal cortical damage in addition to medial temporal lobe pathology. A common interpretation of extensive, ungraded RA is that damage has occurred to knowledge stores, thereby affecting the ability to recollect information regardless of when it was learned (Kapur, 1993; Kapur et al., 1996).

E.P.'s RA was not so severe as G.T.'s. His RA was severe and extensive, but unlike G.T., E.P. was capable of considerable recall from his early life. Thus, unlike other patients with postencephalitic amnesia (e.g., patients D.R.B., S.S., and R.F.R.) who are described as incapable of episodic remembering, E.P.'s narrative episodes from his early life contained the same kind of detail and structure as the narrative episodes recalled by our control subjects (Table 4). Inevitably, the question arises whether the narratives produced by severely amnesic patients are true remembrances or whether they are drawn from a collection of a few over-rehearsed stories (cf. Cermak and O'Connor, 1983). In view of the fact that even recollections from healthy individuals often have this character, it is unclear how to decide the point. E.P. does appear to be capable of autobiographical remembering, although we recognize that methods might yet be devised to show that his recollections are somehow impoverished or imperfect, in comparison with those of healthy persons.

E.P.'s severe and extensive RA is likely attributable to the fact that his lesion includes the medial temporal cortex (perirhinal and parahippocampal cortices), not just the hippocampal formation, and it also extends laterally from the medial temporal lobe to include the fusiform gyrus at some levels. At the same time, E.P.'s residual capacity for very remote memory is probably attributable to the fact that his lesion did not extend as far into lateral temporal cortex as the lesion in G.T. or other patients with pervasive impairments of episodic remembering. Thus, it is possible that damage in addition to the hippocampal formation that includes medial temporal cortex and fusiform gyrus is sufficient to cause severe and extensive RA. Such damage appears to spare both episodic and semantic remembering of facts and events from early life so long as the damage does not include more lateral temporal cortex.

It is also worth noting that both E.P. and G.T. performed differently on the Famous Name Completion test and the Famous Names Recognition test than the postencephalitic patient R.F.R. (Warrington and McCarthy, 1988). R.F.R. exhibited no deficit at all when tests about famous persons were redesigned to assess simple familiarity for names or name completion ability. E.P. and G.T., as well as two patients studied previously (patient W.I. and patient D.R.B.; Squire et al., 1990), improved their performance when the tests were administered in the revised format, but they remained distinctly impaired. The revised test was rather easy for R.F.R., and ceiling effects might have obscured an impairment. Alternatively, the neuropathology responsible for R.F.R.'s impairment may prove to be different in some important way from that of the other four patients who have been given these tests.

In summary, the findings suggest that RA can be quite limited or very extensive, depending on whether the damage is restricted to the hippocampal formation or also involves additional temporal cortex. At the same time, it must be emphasized that the number of patients with medial temporal lobe lesions or even larger temporal lobe lesions who have been studied carefully with respect to RA is small, and an even smaller number of patients have been studied postmortem to obtain neurohistological data about the extent of the lesion.

\section{REFERENCES}

Albert MS, Butters N, Levin J (1979) Temporal gradients in the retrograde amnesia of patients with alcoholic Korsakoff's disease. Arch Neurol 36:211-216.

Barr WB, Goldberg E, Wasserstein J, Novelly RA (1990) Retrograde amnesia following unilateral temporal lobectomy. Neuropsychologia 28:243-256.

Beatty WW, Salmon DP, Bernstein N, Butters N (1987) Remote memories in a patient with amnesia due to hypoxia. Psychol Med 17:657-665.

Cermak LS, O'Connor M (1983) The anterograde and retrograde retrieval ability of a patient with amnesia due to encephalitis. Neuropsychologia 19:213-224.

Cohen N, Squire LR (1981) Retrograde amnesia and remote memory impairment. Neuropsychologia 119:337-356.

Corkin S (1984) Lasting consequences of bilateral medial temporal lobectomy: clinical course and experimental findings in H.M. Semin Neurol 4:249-259.

Crovitz HF, Schiffman H (1974) Frequency of episodic memories as a function of their age. Bull Psychonom Soc 4:517-518. 
Damasio AR, Eslinger PJ, Damasio H, Van Hoesen GW, Cornell S (1985) Multimodal amnesic syndrome following bilateral temporal and basal forebrain damage. Arch Neurol 42:252-259.

Gabrieli J, Cohen N, Corkin S (1988) The impaired learning of semantic knowledge following bilateral medial temporal-lobe resection. Special issue: single-case studies in amnesia: theoretical advances. Brain Cogn 7:157-177.

Glisky EL, Schacter DL, Tulving E (1986) Computer learning by memory-impaired patients: acquisition and retention of complex knowledge. Neuropsychologia 24:313-328.

Hamann SB, Squire LR (1995) On the acquisition of new declarative knowledge in amnesia. Behav Neurosci 109:1027-1044.

Hamann SB, Squire LR, Stefanacci L, Adolphs R, Damasio H, Damasio A (1996) Intact perception of facial emotion despite bilateral amygdala lesions. Nature 379:497.

Hodges JR (1994) Retrograde amnesia. In: Handbook of memory disorders (Baddeley A, Wilson BA, Watts F, eds), pp 81-107. New York: Wiley.

Johnson MK, Foley MA, Suengas AG, Raye CL (1988) Phenomenal characteristics of memories for perceived and imagined autobiographical events. J Exp Psychol Gen 117:371-376.

Johnson MK, O'Connor M, Cantor J (1997) Confabulation, memory deficits, and frontal dysfunction. Brain Cogn 4:189-206.

Kaplan EF, Goodglass H, Weintraub S (1983) The Boston naming test. Philadelphia: Febiger.

Kaplan EF, Fein D, Morris R, Delis D (1991) WAIS-R as a neuropsychological instrument. New York: Psychological Corporation.

Kapur N (1993) Focal retrograde amnesia in neurological disease: a critical review. Cortex 29:217-234.

Kapur N, Scholey K, Moore E, Barker S, Brice J, Thompson S, Shiel A, Carr R, Abbot P, Fleming J (1996) Long-term retention deficits in two cases of disproportionate retrograde amnesia. J Cogn Neurosci 8:416-434.

Kartsounis LD, Rudge P, Stevens JM (1995) Bilateral lesions of CA1 and CA2 fields of the hippocampus are sufficient to cause a severe amnesic syndrome in humans. J Neurol Neurosurg Psychiatry 59:95-98.

Kopelman MD, Wilson BA, Baddeley AD (1989) The autobiographical memory interview: a new assessment of autobiographical and personal semantic memory in amnesic patients. J Clin Exp Neuropsychol 5:724-744.

Kritchevsky M, Squire LR, Zouzounis JA (1988) Transient global amnesia: characterization of anterograde and retrograde amnesia. Neurology 38:213-219.

MacKinnon D, Squire LR (1989) Autobiographical memory in amnesia. Psychobiology 17:247-256.

Marslen-Wilson WD, Teuber HL (1975) Memory for remote events in anterograde amnesia: recognition of public figures from news photographs. Neuropsychologia 13:353-364.

Nadel L, Moscovitch M (1997) Memory consolidation, retrograde amnesia, and the hippocampal complex. Curr Opin Neurobiol 7:217-227.

Osterrieth PA (1944) Le test de copie d'une figure complexe [The test of copying a complex figure]. Arch Psychol 30:206-356.

Penfield W, Mathieson G (1974) Memory: autopsy findings and comments on the role of hippocampus in experiential recall. Arch Neurol 31:145-154.

Rempel-Clower N, Zola SM, Squire LR, Amaral DG (1996) Three cases of enduring memory impairment following bilateral damage limited to the hippocampal formation. J Neurosci 16:5233-5255.

Rey A (1964) L'examen clinique psychologie [The clinical examination in psychology]. Paris: Presses Universitaires de France.
Ribot T (1881) Les maladies de la memoire [Diseases of memory]. New York: Appleton-Century-Crofts.

Salmon HI, Lasker BR, Butters N, Beatty WW (1988) Remote memory in a patient with circumscribed amnesia. Brain Cogn 7:201-211.

Sanders HI, Warrington DK (1971) Memory for remote events in amnesic patients. Brain 94:661-668.

Schacter DL, Harbluk JL, McLachlan DR (1984) Retrieval without recollection: an experimental analysis of source amnesia. J Verb Learn Verb Behav 23:593-611.

Schmidtke K, Vollmer H (1997) Retrograde amnesia: a study of its relation to anterograde amnesia and semantic memory deficits. Neuropsychologia 35:505-518.

Schnider A, Regard M, Landis T (1994) Anterograde and retrograde amnesia following bitemporal infarction. Behav Neurol 7:87-92.

Shimamura AP, Squire LR (1987) A neuropsychological study of fact memory and source amnesia. J Exp Psychol Learn Mem Cogn 13:464-473.

Squire LR (1975) A stable impairment in remote memory following electroconvulsive therapy. Neuropsychologia 13:51-58.

Squire LR (1992) Memory and the hippocampus: a synthesis from findings with rats, monkeys, and humans. Psychol Rev 99:195-231.

Squire LR, Alvarez P (1995) Retrograde amnesia and memory consolidation: a neurobiological perspective. Curr Opin Neurobiol 5:169-177.

Squire LR, Knowlton BJ (1995) Learning about categories in the absence of memory. Proc Natl Acad Sci USA 92:12470-12474.

Squire LR, Shimamura AP (1986) Characterizing amnesic patients for neurobehavioral study. Behav Neurosci 100:866-877.

Squire LR, Haist F, Shimamura AP (1989) The neurology of memory: quantitative assessment of retrograde amnesia in two groups of amnesic patients. J Neurosci 9:828-839.

Squire LR, Amaral DG, Press GA (1990) Magnetic resonance measurements of hippocampal formation and mammillary nuclei distinguish medial temporal lobe and diencephalic amnesia. J Neurosci 10:3106-3117.

Vargha-Khadem F, Gaffan D, Watkins KE, Connelly A, Van Paesschen W, Mishkin M (1997) Differential effects of early hippocampal pathology on episodic and semantic memory. Science 277:376-380.

Verfaellie M, Reiss L, Roth HL (1995) Knowledge of New English vocabulary in amnesia: an examination of premorbidly acquired semantic memory. J Int Neuropsychol Soc 1:443-453.

Victor M, Agamanolis J (1990) Amnesia due to lesions confined to the hippocampus: a clinical-pathological study. J Cogn Neurosci 2:246-257.

Victor M, Angevine JB, Mancall EL, Fisher CM (1961) Memory loss with lesions of hippocampal formation. Arch Neurol 5:244-263.

Warrington EK (1984) Recognition memory test. Windsor, Ontario, Canada: FER-Nelson.

Warrington EK (1996) Studies of retrograde memory: a long-term view. Proc Natl Acad Sci USA 93:13523-13526.

Warrington EK, Duchen LW (1992) A re-appraisal of a case of persistent global amnesia following right temporal lobectomy: a clinicopathological study. Neuropsychologia 5:437-450.

Warrington EK, McCarthy RA (1988) The fractionation of retrograde amnesia. Brain Cogn 7:184-200.

Zola-Morgan S, Cohen NJ, Squire LR (1983) Recall of remote episodic memory in amnesia. Neuropsychologia 21:487-500.

Zola-Morgan S, Squire LR, Amaral DG (1986) Human amnesia and the medial temporal region: enduring memory impairment following a bilateral lesion limited to field CA1 of the hippocampus. J Neurosci 6:2950-2967. 